galactokinase galactose erythrocytes galactitol galactose-1-phosphate

uridyltransferase hereditary disease

uridine diphospho-

galactose

4-epimerașe

\title{
Hereditary Galactokinase Deficiency, a Newly Recognized Cause of Juvenile Cataracts ${ }^{31}$
}

\author{
R. Grtzelmann \\ Laboratory for Metabolic Research, University Pediatric Department, \\ Kinderspital, 8032 Zürich, Switzerland
}

\begin{abstract}
Extract
Two patients with cataracts and a defect in galactose metabolism were studied. A hemolysate of erythrocytes respired well on galactose-1-phosphate. Galactose-1-phosphate uridyltransferase activity in red cells was normal and uridine diphosphogalactose 4-epimerase was also active. Erythrocyte galactokinase activity was completely absent in both patients (fig. 1). Only insignificant amounts of ${ }^{14} \mathrm{CO}_{2}$ were formed from galactose- $1-{ }^{14} \mathrm{C}$ by the patients' hemolysates (table $\mathrm{I}$ ).

After a breakfast containing $850 \mathrm{ml}$ of milk was taken by one patient, the galactose level in blood rose from 7.6 to a maximum of $44.9 \mathrm{mg} / 100 \mathrm{ml}$ at 60 minutes and was still at $32.1 \mathrm{mg} / 100 \mathrm{ml} \mathrm{l} 1 \frac{1}{2}$ hours later, while that of glucose rose from 90 to $136 \mathrm{mg} / 100 \mathrm{ml}$ at 60 minutes and then dropped (fig. 2).

In the hour preceding the load, the patient excreted $0.36 \mathrm{~g}$ of galactose, $0.63 \mathrm{~g}$ of galactitol and 0.04 $\mathrm{g}$ of glucose; within 150 minutes after breakfast he excreted $1.90 \mathrm{~g}, 0.83 \mathrm{~g}$ and $0.72 \mathrm{~g}$ respectively. Galactose and galactitol concentrations were remarkably high in the one hour portion before the load $(0.45$ and $0.77 \mathrm{~g} / 100 \mathrm{ml}$ respectively).

One patient drank 3 liters of milk a day over a period of 5 days. Total urinary output was $191.51 \mathrm{~g}$ of galactose and $47.97 \mathrm{~g}$ of galactitol which together are almost equivalent to $2 / 3$ of the ingested galactose from milk (table III). The daily ranges of urinary loss of these two compounds were remarkably narrow and the ratio of urinary galactitol to urinary galactose was $1: 4$ and constant.

Within the same time $2.4 \mathrm{~g}$ of glucose were excreted in a total of $9980 \mathrm{ml}$ of urine. Amino acid excretion was normal. During this 5 day study period, daily urinary excretion of total nitrogen was 19.6-22.3 $\mathrm{g}$ while that of $\alpha$-amino nitrogen was $124.3-191.1 \mathrm{mg}$, both considered to be at the upper limit of the norm. Creatinine excretion ranged from $882 \mathrm{mg}$ to $1139 \mathrm{mg}$ per day.

The parents of the patients were related (fig. 3). The youngest brother of the patients and his family as well as the 4 living children of the oldest patient and their families were studied for galactokinase activity. A group of one hundred normal subjects served as controls (table IV).

In normal subjects galactokinase activity ranged from 0.138 to 0.359 with an average of 0.257 $(2 \sigma=0.083) \mu$ moles galactose phosphorylated $/ \mathrm{ml} \mathrm{RBC} / \mathrm{hr}$.

In the family of the patients (fig.4) the results of the enzyme assays fell into 3 groups: the 2 patients with virtually complete enzyme deficiency; some of their relatives with intermediary values; and others within a wide range above $0.240 \mu \mathrm{moles} / \mathrm{ml} / \mathrm{hr}$. The 4 children of the oldest patient, 26 to 38 years of age, had activities of 0.131 to $0.145 \mu \mathrm{moles} / \mathrm{ml} / \mathrm{hr}$, and the youngest brother of the patients, at the age of 38 years, had an activity of 0.154 , values clearly below those of the members of the control group (fig. 5). One grandchild of the oldest patient as well as four of the six children of her youngest brother, aged 11 to 16 years, also had low activities.
\end{abstract}


In the blood cells of the 2 patients studied here a virtually complete absence of galactokinase activity was demonstrated. After milk ingestion, extraction of galactose from the blood in the youngest patient was extremely slow. Thus, one would assume that galactokinase activity in the liver of this patient was absent or at least reduced to a minimum.

The results of the assays of erythrocyte galactokinase in the family of the patients are consistent with inheritance of the defect as an autosomal recessive trait.

The deficiency or the heterozygous state may be factors related to the formation of cataracts beyond infancy and childhood.

\section{Speculation}

The study of patients with galactokinase deficiency will provide new insights into the intermediary galactose metabolism in man.

Prevention of cataract formation due to galactokinase deficiency must be sought; it may be attained by the screening of the newborn population for hypergalactosemia and by the immediate removal of all galactose from the diet.

\section{Introduction}

Cataracts in infants and children originate from various causes. Some are the result of an embryopathy and are congenital. Others, which appear in infancy or early childhood, have been linked to metabolic disorders such as hypoparathyroidism, Lowe's syndrome and galactosemia.

Galactokinase deficiency as a cause of juvenile cataracts has come to light only recently [11]. The first patient in whom this defect was demonstrated had been studied many years ago and was found to have galactose diabetes [9]. He and several members of his family have been located and re-studied. The evidence gathered suggests that the defect is transmitted genetically. Information on how the patient handles high galactose loads in his diet has been obtained.

\section{Materials and Methods}

All chemicals were reagent grade. Galactose- $1-{ }^{14} \mathrm{C}$ (8.32 $\mathrm{mc} / \mathrm{mmole})$ and uridine diphosphogalactose (galactose $-{ }^{14} \mathrm{C}$, u. $1.120 \mathrm{mc} / \mathrm{mmole}$ ) were obtained from the New England Nuclear Corp., Boston; glucose- $1-{ }^{14} \mathrm{C}$ ( $33.2 \mathrm{mc} / \mathrm{mmole}$ ) was obtained from Calbiochem, Los Angeles. Glucose in blood was estimated by the glucose oxidase procedure (test combination Boehringer, Mannheim, Germany), galactose in blood was estimated with galactose oxidase (Ames Co., Elkhart, Indiana) according to RoTH et al. [22], and erythrocyte galactose-1-phosphate was measured enzymatically [17].

In urine, total nitrogen was determined by a microKjeldahl procedure, $\alpha$-amino nitrogen by a ninhydrin method [15] and creatinine by the Jaffé reaction; semiquantitative screening for aminoaciduria was conducted by high voltage electrophoresis on paper [6].

Galactose, glucose and galactitol in urine were detected by routine paper and thin layer chromatography and were estimated in the following way: 50 to $100 \mu \mathrm{l}$ portions of urine were chromatographed on Whatman No.3 paper using ethylacetate/pyridine/ water $(10 / 4 / 3$, vol. by vol.) as the solvent; the glucosegalactose-galactitol regions were eluted with water in the cold and dried in vacuo. The three compounds were measured by gas liquid chromatography of the trimethylsilylation products [3] as described earlier [12]. Recovery of urinary hexoses was studied by admixing known amounts of galactose and galactitol to urine from a normal subject and testing it by the same procedure; recovery of galactose and galactitol was within $2 \%$ and $6 \%$ of the total respectively.

The enzyme assay procedures performed on the patients' blood cells are indicated in the text.

\section{Case Histories and Clinical Findings}

Case 1: H. K., a male, now 44 years of age, was affected with von Recklinghausen's neurofibromatosis. He was supposed to have had 'grey eyes' at the age of 8 to 9 months. Discisions were performed on both eyes at the age of 6 years. At the age of 9 , secondary cataracts had developed, and a further operation was performed in 1932 in the Department of Ophthalmology, University of Zurich. Mellituria was discovered and the patient was transferred to the Pediatric Department for evaluation and treatment of diabetes. The observation that the patient excreted sugar in his urine mainly after ingestion of milk prompted chemical identification of 
the sugar. This proved to be galactose [9]. It was reported that up to $80 \%$ of ingested galactose was lost in the urine, and even small loads (i.e. $2 \mathrm{~g}$ ) of galactose caused galactosuria. Mellituria disappeared upon elimination of all milk from the diet.

Dietary restrictions were recommended but never followed. Secondary cataracts again developed bilaterally, and the patient has spent most of his adult life in a home for the blind. Persistent complaints of weakness and pains in arms, legs and back were attributed to the presence of neurofibromatosis. Eleven years ago a myxo-sarcoma was removed. Two years ago, when the patient participated in a screening drive for diabetes mellitus, mild glucosuria was discovered through the use of a glucose oxidase paper strip (Tes-Tape ${ }^{\circledR}$ ). He then avoided sweets for some time.

When he was last seen, the patient had just light perception with false projection and was practically blind. There was marked nystagmus. He regularly drank one-half to one liter of milk for breakfast and the same amount for dinner without experiencing discomfort. Intake of fluids other than milk was moderate. Nocturia occurred occasionally. Extreme fatigue and pains occurred at all times of the day and sometimes at night with no apparent relation to food intake. No change was noted when the patient avoided milk for two days. His intelligence appeared to be within the norm. He repeatedly granted permission to collect blood and urine specimens.

There were numerous naevi and fibromata in his skin, which was colored grey-brown in the areas exposed to light and very pale in the covered parts.

His hand lines and the mucosa of his mouth were normally pigmented. Liver and spleen were not enlarged.

The urine of this patient, voided two hours after breakfast, gave a strongly positive Benedict reaction and a weakly positive reaction with Tes-Tape ${ }^{\circledR}$. Paper chromatograms indicated a galactose concentration of about $2 \mathrm{~g} / 100 \mathrm{ml}$ and a glucose concentration of approximately $0.05 \mathrm{~g} / 100 \mathrm{ml}$. Aminoaciduria as judged by high voltage electrophoresis on paper was normal. However, surprisingly high concentrations of urinary galactitol were demonstrated [12]. The level of glucose in blood during fasting was $90 \mathrm{mg} / 100 \mathrm{ml}$; that of galactose was 8.0 and $7.6 \mathrm{mg} / 100 \mathrm{ml}$. Glycoprotein and lipoprotein concentrations in serum were increased, but immunoproteins were normal. Normal titers of iso-agglutinins anti-A and anti-B in serum were found. The erythrocyte galactose-1-phosphate content approached zero.
Case 2: M.F.-K., a 64-year-old female, was the oldest sister of H.K. It is not known at what age cataracts appeared in this patient, but surgery had been performed on her right eye when she was hospitalized in 1909 at the Department of Ophthalmology at the Uni-

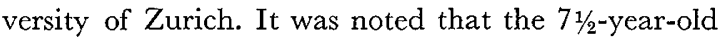
child was extremely skinny and appeared to be mentally retarded. She had a typical zonular cataract on her left eye, and a secondary cataract had developed after discision on her right eye. Discision was again performed on the right eye and the operation proved to be successful. At that time her urine was not examined.

This patient could never read or write, probably because of a lack of schooling. She never experienced the severe fatigue which plagued her brother. She was married and had six children, four of whom were alive and healthy. Just recently she had arthritic pains in her fingers, and mild osteoporosis was seen on a recent $x$-ray of her hand. Her daily intake of milk was very limited (some milk in her breakfast coffee), but she had no dislike for milk and did not experience any discomfort after its ingestion.

At the present the patient appeared to be normally intelligent and in reasonably good health. She was strangely shy and cautious in establishing personal contact. Coloration of the exposed parts of her skin was a greyish yellow while the unexposed parts were white. Several penny-sized pigmented naevi were located on her arms, but only two tiny fibromata were visible on her neck and shoulder. An inhomogeneous grey opacity was seen behind her left pupil, and her left visual acuity was extremely poor. No opacities were seen in her right eye and her sight was good.

A venous blood specimen was drawn for biochemical analysis. The glucose level in venous blood, measured 4 to 5 hours after breakfast, was $90 \mathrm{mg} / 100 \mathrm{ml}$; that of galactose was $1.6 \mathrm{mg} / 100 \mathrm{ml}$. Erythrocyte galactose-1phosphate was $0.6 \mathrm{mg} / 100 \mathrm{ml}$. A urine specimen, voided $1 \frac{1}{2}$ hours after a light breakfast including only a little milk, gave a weakly positive Benedict reaction and a negative glucose oxidase reaction. Paper chromatography revealed the presence of galactose at a concentration of approximately $0.04 \mathrm{~g} / 100 \mathrm{ml}$ and the absence of glucose; gas liquid chromatography of the eluate from the glucose-galactose region on the paper gave a galactose concentration of $0.05 \mathrm{~g} / 100 \mathrm{ml}$ and a galactitol concentration of $0.03 \mathrm{~g} / 100 \mathrm{ml}$ of urine.

Case 3: A. L.-K., a 62-year-old female, was the sister of H.K. and of M.F.-K. and the second oldest child. Although she was not available for study, her case is included here because her history was remarkably similar to that of her siblings.

She was hospitalized in 1909 at the Department of Ophthalmology with hersister. She was then $5 \frac{1}{2}$ years 
old and as skinny as her sister, and she too was considered mentally retarded. Dense zonular cataract was present on both eyes. Discision was performed three times on her right eye. According to the medical records, after the first of these operations some swelling of the lens occurred, and it was considered unusual, that such swelling was restricted to the inner rather than the outer strata of the lens. This patient, too, was married and had seven children, of whom six were alive; none of these persons were available for study.

\section{Biochemical Investigations}

\section{The Biochemical Lesion}

Case 1, H.K.: The patient's hemolysa te, in the micromanometric assay procedure of Schwarz [23], respired well on galactose-1 - phosphate. Galactose-1 phosphate uridyltransferase activity in red cells, as measured by a modification [5] of the uridine diphosphoglucose consumption procedure [2], was normal, and uridine diphosphogalactose 4-epimerase was also active [12]. Galactokinase activity was assayed by incubation of the intact red blood cells with ${ }^{14} \mathrm{C}$-labeled galactose for 2 minutes followed by chromatography of the reaction products (RoBinson [21]) using red cells of a normal subject and of a child with galactosemia for comparison. As can be seen from fig. 1, no galactokinase activity was demonstrated. Accordingly, galactokinase activity in the hemolysate when assayed by the method of $\mathrm{NG}_{\mathrm{G}}$ et al. [18] was virtually absent. Similarly, when $2 \mathrm{ml}$ samples of whole blood lysates were incubated for 90 minutes with galactose- $1-{ }^{14} \mathrm{C}$

Table I. Oxidation of galactose- $1-{ }^{14} \mathrm{C}$ and of glucose-1${ }^{14} \mathrm{C}$ by lysates of whole blood from patients H.K. and M.F.-K. Assay procedure according to WeINBERG [27]

\begin{tabular}{|c|c|}
\hline Galactose- $1-{ }^{14} \mathrm{C} \cdot$ & $\begin{array}{l}{ }^{14} \mathrm{CO}_{2} \text { c.p.m. } / 2 \mathrm{ml} \mathrm{whole} \\
\text { blood Iysate } / 90 \mathrm{~min} .\end{array}$ \\
\hline Normal subject . & 91,120 \\
\hline H.K. . . . . & 307 \\
\hline Pooled ( $1 \mathrm{mI}$ of each) & 11,360 \\
\hline Galactose- $1-{ }^{14} \mathrm{C}$ & $\begin{array}{l}{ }^{14} \mathrm{CO}_{2} \text { c.p.m. } / 2 \mathrm{ml} \text { whole } \\
\text { blood lysate } / 90 \mathrm{~min} .\end{array}$ \\
\hline Normal subject . & 150,040 \\
\hline M.F.-K. . . . & 370 \\
\hline Pooled (1 ml of each) & 63,490 \\
\hline Glucose- $1-{ }^{14} \mathrm{C}$. & $\begin{array}{l}{ }^{14} \mathrm{CO}_{2} \text { c.p.m. } / 2 \mathrm{ml} \text { whole } \\
\text { blood lysate } / 90 \mathrm{~min} .\end{array}$ \\
\hline Normal subject . & 9,670 \\
\hline H.K. & 7,000 \\
\hline Pooled ( $1 \mathrm{ml}$ of each) & 8,590 \\
\hline
\end{tabular}

2 Pediat. Res., Vol. 1, No. 1 (1967) according to WEINBERG [27], only insignificant amounts of ${ }^{14} \mathrm{CO}_{2}$ were formed by the patient's hemolysate (table I). To rule out the possibility of an enzyme inhibitor, one $\mathrm{ml}$ portions of hemolysates from a normal subject and from the patient were mixed and ${ }^{14} \mathrm{CO}_{2}$ production by the control hemolysate was measured. The respiratory activity of the control hemolysate apparently was reduced (table I). Subsequent experiments demonstrated, however, that this deficit of
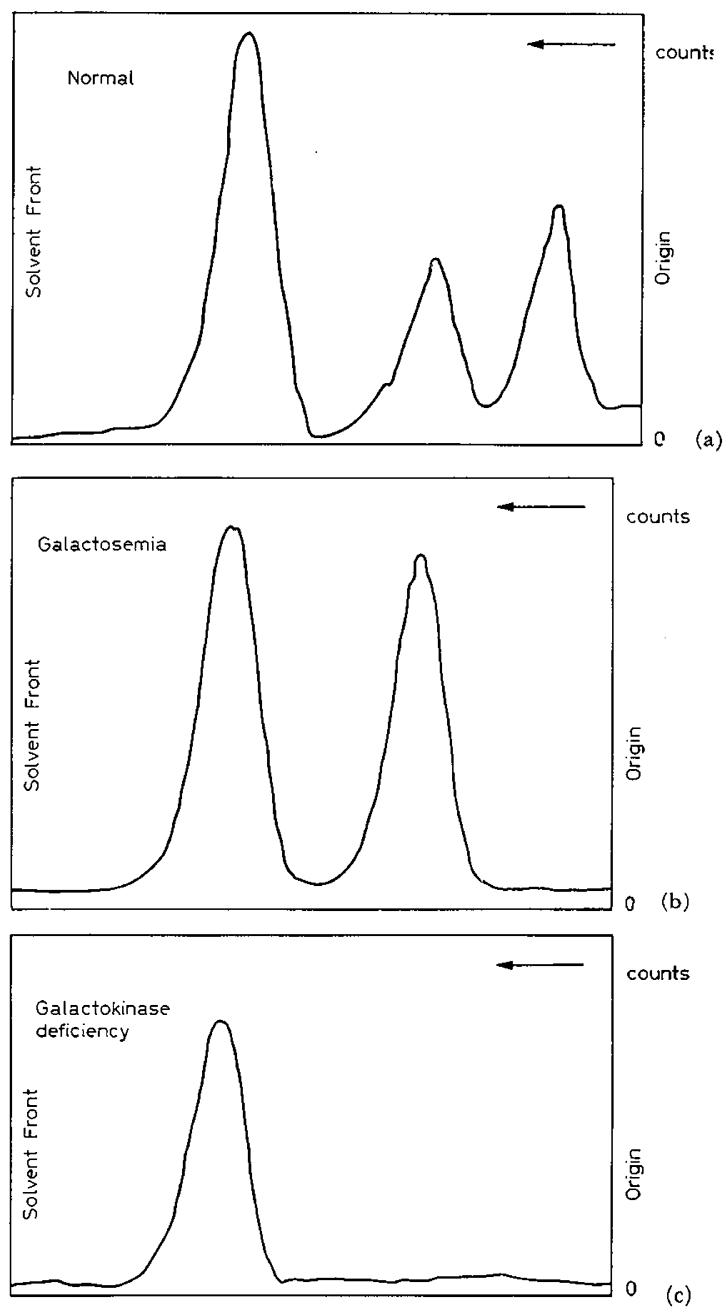

Fig. 1. Radiochromatogram tracings of reaction products separated by paper chromatography following incubation of intact red blood cells with ${ }^{14} \mathrm{C}$-labeled galactose according to Robinson [21]. In the normal subject (a), three major fractions (origin to solvent front) are seen: uridine diphosphohexose, galactose-1phosphate, and galactose. No uridine diphosphohexose is formed by the erythrocytes of a galactosemic individual (b). No phosphorylated intermediates are found on the chromatogram from patient H.K. (c). 
${ }^{14} \mathrm{CO}_{2}$ production by the control hemolysate was caused by the dilution of the isotopically labeled galactose in the reaction mixture with unlabeled galactose from the patient's blood (table II). Thus, galactokinase deficiency in this patient's blood cells was established.

Case 2, M.F.-K.: The same biochemical procedures were applied to this patient's blood cells with similar results. The hemolysate also respired well on galactose1-phosphate. Galactose-1-phosphate uridyltransferase activity in red cells was normal and uridine diphosphogalactose 4-epimerase was active. Galactokinase activity, as assayed by the short term incubation of intact red cells [21], by the method of $\mathrm{NG}_{\text {et }}$ al. [18] and by Weinberg's procedure [27] was virtually absent [table I). It may be noted that this patient's hemolysate did not cause as marked a deficit in ${ }^{14} \mathrm{CO}_{2}$ production by the control hemolysate (table $\mathrm{I}$ ) as did that of $\mathrm{H}$. K., a result well in accord with the lower galactose concentration $(1.6 \mathrm{mg} / 100 \mathrm{ml})$ in this patient's blood.

Table II. Oxidation of galactose-1-14 $\mathrm{G}$ by individual and pooled lysates from a normal subject and from patient H.K. Assay procedure according to WEINBERG [27]

\begin{tabular}{ll}
\hline Whole blood lysates & Galactose ${ }^{14} \mathrm{CO}_{2}$ c.p.m./ \\
& concentra- $2 \mathrm{ml}$ of whole \\
& tion $(\mu \mathrm{g}$ in blood lysate/ \\
& $4 \mathrm{ml}$ of 90 minutes \\
& reaction \\
& mixture) \\
\hline
\end{tabular}

\begin{tabular}{|c|c|c|}
\hline \multicolumn{3}{|l|}{ Individual samples $(2 \mathrm{ml})$ : } \\
\hline Normal subject & 50 & 136,650 \\
\hline H.K., Specimen A & & 550 \\
\hline H.K., Specimen B & & 510 \\
\hline \multicolumn{3}{|l|}{ Pooled samples $(1 \mathrm{ml}$ of each): } \\
\hline Control+Specimen A & 123 & 47,500 \\
\hline Control+Specimen B & 463 & 15,070 \\
\hline $\begin{array}{l}\text { Control }+ \text { Specimen A } \\
\text { (unlabeled galactose added) }\end{array}$ & 523 & 12,490 \\
\hline $\begin{array}{l}\text { Control+Specimen A } \\
\text { (unlabeled galactose added) }\end{array}$ & 923 & 7,040 \\
\hline
\end{tabular}

Incubation flasks contained $0.44 \mu \mathrm{c}$ of labeled galactose throughout; total galactose concentration varied. Dilution of the radioactive galactose by non-labeled galactose resulted in apparent reduction of galactose oxidation by the hemolysate of the healthy control. Blood galactose concentrations were:

Normal subject: $0.7 \mathrm{mg} / 100 \mathrm{ml}$

H.K. fasting, specimen A: $8.0 \mathrm{mg} / 100 \mathrm{ml}$

H.K. 45 minutes after breakfast, specimen B: $42 \mathrm{mg} / 100 \mathrm{ml}$
Metabolic Studies

Neither patient would agree to enter the hospital for clinical studies, but H.K. consented to three very simple tests:

1. Collection of an overnight urine portion: Having drunk his usual milk portion the day before, H.K. voided an entire overnight urine portion one hour before breakfast. The urine was cooled and kept on ice for analysis of urinary galactose, galactitol and glucose. It was found that H.K. had excreted $7.26 \mathrm{~g}$ of galactose, $2.65 \mathrm{~g}$ of galactitol, and $0.45 \mathrm{~g}$ of glucose.

2. Milk tolerance test: One urine portion was collected during the hour before breakfast. Breakfast was taken after an overnight fast and consisted of some coffee, two large pieces of buttered bread and $850 \mathrm{ml}$ of milk (equivalent to about $20 \mathrm{~g}$ of galactose from lactose, assuming a concentration of $4.8 \mathrm{~g} / 100 \mathrm{ml}$ of milk). Glucose and galactose in capillary blood and galactose, galactitol and glucose in urine were estimated before breakfast and followed for $21 / 2$ hours at 30 minute intervals. A normal subject was subjected to the same test, In the patient, the galactose level in blood rose from 7.6 to a maximum of $44.9 \mathrm{mg} / 100 \mathrm{ml}$ after 60 minutes and was still at $32.1 \mathrm{mg} / 100 \mathrm{ml}$ after $21 / 2$ hours, while that of glucose rose from 90 to $136 \mathrm{mg} / 100 \mathrm{ml}$ after 60 minutes and then dropped (fig. 2). In the control person, the galactose level in blood was just measurable with a maximum of $5.0 \mathrm{mg} / 100 \mathrm{ml}$ after 30 minutes, and that of glucose showed a normal biphasic response.
Patient H.K.
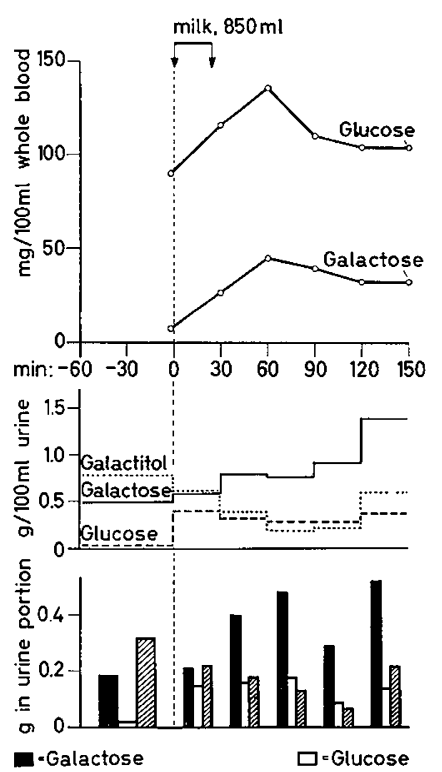

Normal subject

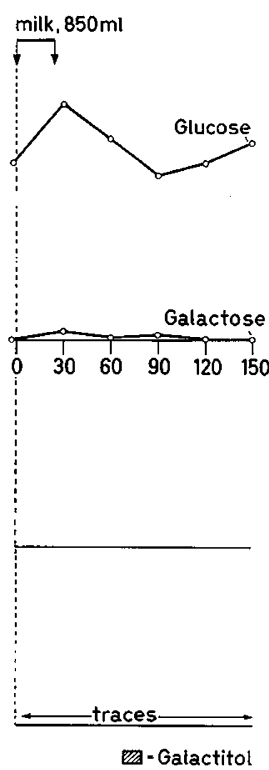

Fig.2. Milk tolerance test in patient H.K. and in a normal subject. 
Only traces of urinary hexoses and of lactose were excreted by the normal subject after the load. In the hour preceding the load, the patient excreted $0.36 \mathrm{~g}$ of galactose, $0.63 \mathrm{~g}$ of galactitol and $0.04 \mathrm{~g}$ of glucose; within 150 minutes after the load he excreted $1.90 \mathrm{~g}$, $0.83 \mathrm{~g}$ and $0.72 \mathrm{~g}$ respectively. Galactose and galactitol concentrations were remarkably high in the one -hour portion before the load $(0.45$ and $0.77 \mathrm{~g} / 100 \mathrm{ml}$ respectively).

3. Prolonged high milk intake: H. K. agreed to drink as much milk as he would like over a period of 5 days. $\mathrm{He}$ chose to drink exactly 3 liters a day, one half for breakfast and one half for dinner. From the first to the fifth day all urine was collected, cooled and kept at $-20^{\circ} \mathrm{C}$ for estimation of galactose, galactitol, glucose, total nitrogen, $a$-amino nitrogen and creatinine levels. Assuming again a concentration of $4.8 \mathrm{~g}$ of lactose per $100 \mathrm{ml}$ of cow milk, H. K. ingested $720 \mathrm{~g}$ of lactose i. e. $360 \mathrm{~g}$ of galactose from milk lactose over a period of 5 days.

Fig. 3. The family of the two patients: case 1 is the propositus, case 2 is his oldest and case 3 his second oldest sister.

$\square \bigcirc$ male, female, not examined

Ш (1) normal erythrocyte galactokinase activity

DD reduced erythrocyte galactokinase activity, presumable heterozygotes

galactokinase deficient patients

-0 individuals with cataracts, not examined
Table III. Amounts of galactose and of galactitol excreted in urine by H.K. During 5 days of high milk intake ( 31 per day)

\begin{tabular}{|c|c|c|}
\hline & Daily range & Total of 5 days \\
\hline Galactose & $35.00-42.05 \mathrm{~g}$ & $191.51 \mathrm{~g}$ \\
\hline Galactitol & $8.34-10.58 \mathrm{~g}$ & $47.97 \mathrm{~g}$ \\
\hline
\end{tabular}

Total urinary output during the 5 days was $191.51 \mathrm{~g}$ of galactose and $47.97 \mathrm{~g}$ of galactitol which together are almost the equivalent of $2 / 3$ of the ingested galactose from milk (table III). The daily ranges of urinary loss of these two compounds were remarkably narrow and the ratio of urinary galactitol to urinary galactose was $1: 4$ and constant.

Within the same time, $2.4 \mathrm{~g}$ of glucose were excreted in a total of $9980 \mathrm{ml}$ of urine. Amino acid excretion, as judged by high voltage electrophoresis on paper, was normal. During the 5 days, daily urinary excretion of total nitrogen was $19.6-22.3 \mathrm{~g}$, that of $\alpha$-amino nitrogen 124.3-191.1 mg, both considered to be at the upper limit of the norm. Creatinine excretion ranged from $882 \mathrm{mg}$ to $1139 \mathrm{mg}$ per day. No ill effects were experienced by the patient.

\section{Family Study}

As is shown in fig. 3 the parents of the three cases (H.K., the propositus; M.F.-K. and A.L.-K.) were related. One sibling of the patients was said to have had cataracts. The 86-year-old mother was alive and was said to have had skin lesions suggesting neurofibroma-

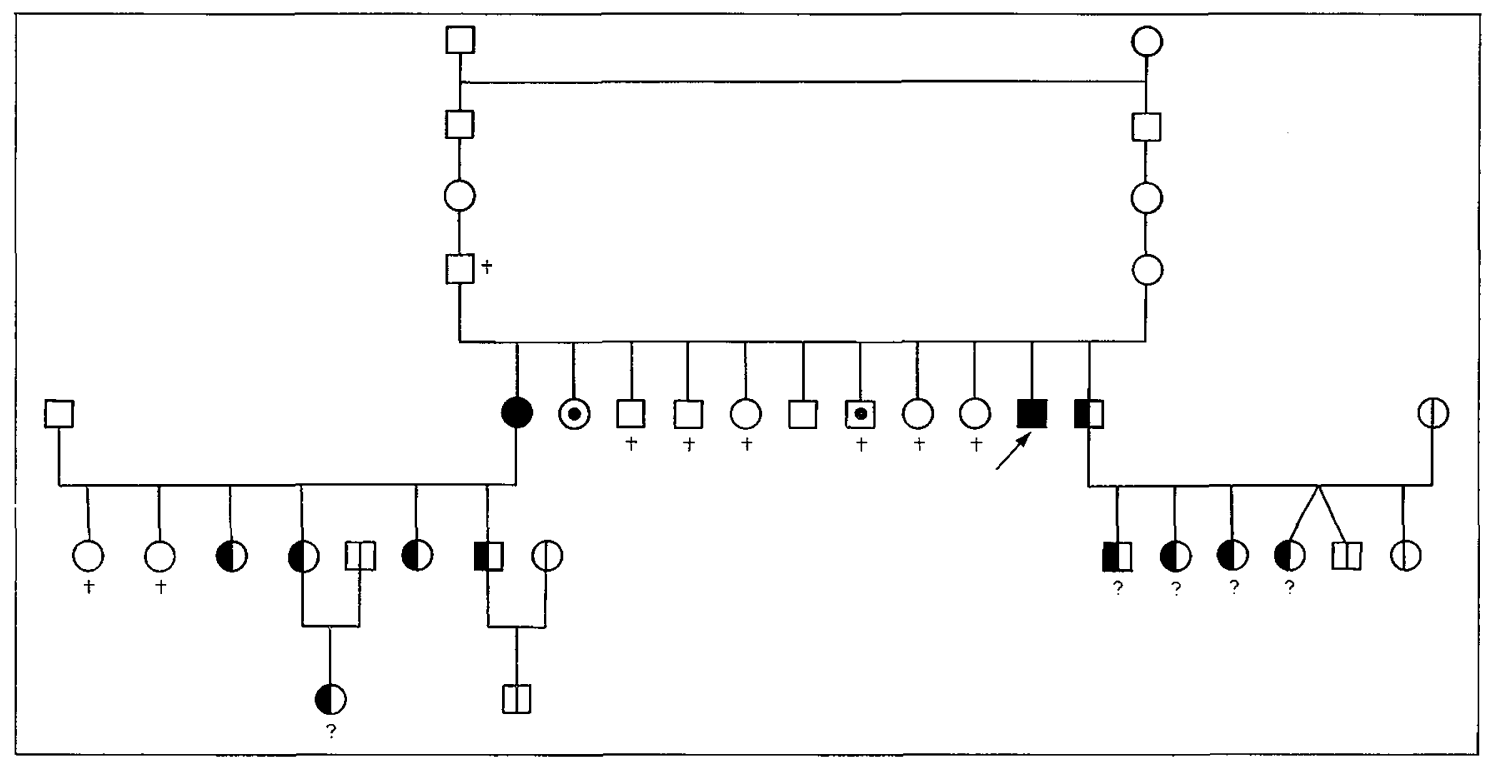


Table IV. Galactokinase activity of red cell lysates in 4 members of the control group. Results of repeated assays

\begin{tabular}{|c|c|c|}
\hline Subject Sex & Age & $\begin{array}{l}\text { Activity ( } \mu \text { moles galactose } \\
\text { phosphorylated per ml RBC } \\
\text { per h) }\end{array}$ \\
\hline R.G. $\pi$ & 36 years & $\begin{array}{lllll}0.325 & 0.337 & 0.310 & 0.296 & 0.319\end{array}$ \\
\hline I.S. $\quad$ q & 40 years & $\begin{array}{lllll}0.254 & 0.228 & 0.254 & 0.270\end{array}$ \\
\hline A.P. $\pi$ & 28 years & $\begin{array}{lll}0.179 & 0.197 & 0.218\end{array}$ \\
\hline M.D. 오 & 19 years & $\begin{array}{lll}0.138 & 0.133 & 0.150\end{array}$ \\
\hline
\end{tabular}

tosis. The father died of an unknown cause. Both were descendants of a highly inbred clan of migrating people said to be Gypsies. For the first 4 generations depicted in fig. 3 only 5 different family names are listed. When in 1850, the Swiss Federal Government ordered every community to naturalize all homeless people found within its boundaries [4], some members of this clan (fig. 3, 2nd generation) settled in various communities to the north and the south of the Alps. Others, however, have apparently remained without permanent residence.

The youngest brother and his family as well as the 4 living children of M.F.-K and their families agreed to have a blood sample drawn. A group of one hundred volunteers, normal subjects of either sex recruited from public schools and from the hospital staff, served as controls. This group also included four small hospitalized children with non-metabolic disorders. Venous blood was kept on ice in heparinized tubes (500 units of heparin per $10 \mathrm{ml}$ of blood) for not longer than 5 hours prior to the assay of galactokinase activity in the red cell lysate. The method of NG et al. [18] in slightly modified form was used. For part of the investigation sonication of packed erythrocytes replaced the freezing and thawing procedure, and incubation of the red cell lysates with ${ }^{14} \mathrm{C}$-labeled galactose was carried out over a period of 45 minutes, three or more measurements being taken. In order to obtain some information about the extent of day-to-day variations in individual persons, 4 members of the control group were tested repeatedly at intervals of 3-8 weeks. The results of these assays are given in table IV. As can be seen, the values obtained in the first determination were followed by values within a narrow range of the first ones.

In the group of normal subjects (fig. 4), galactokinase activity ranged from 0.138 to 0.359 with an average of $0.257(2 \sigma=0.083) \mu$ moles galactose phosphorylated/ $\mathrm{ml} \mathrm{RBC} / \mathrm{h}$. If the 2 lowest values are excluded, the range is 0.179 to 0.359 with an average of $0.260(2 \sigma=$ $0.077) \mu \mathrm{moles} / \mathrm{ml} / \mathrm{h}$. The lowest result was obtained in a 19-year-old female (M.D., table IV). Her parents and the parents of her mother were also examined. The mother and grandfather had somewhat low values (fig. 4, family D.-N.).

In the family of the patients (fig. 4, family K.-G.), the results of the enzyme assays fell into 3 groups: the 2 patients with virtually complete enzyme deficiency; some of their relatives with intermediary values; and some others within a wide range above $0.240 \mu$ moles/ $\mathrm{ml} / \mathrm{h}$. The 4 children of the oldest patient M.F.-K., 26 to 38 years of age, had activities of 0.131 to 0.145 $\mu \mathrm{moles} / \mathrm{ml} / \mathrm{h}$, and the youngest brother of the patients, at the age of 38 years had an activity of 0.154 . These values were clearly below those of the members of the control group, a fact that is best demonstrated in fig. 5 where activities are plotted against age. One grandchild of patient M.F.-K., as well as 4 of the 6 children of her youngest brother, also had low activities whereas their mother had the highest activity of all persons tested. For these children, aged 11 to 16 years, the difference from the control group was obvious but not quite as marked.

Family D. $-N ., \quad \times \quad \times \times, \times, \times$

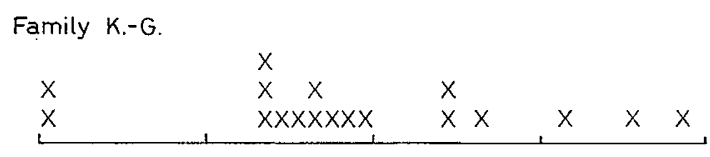

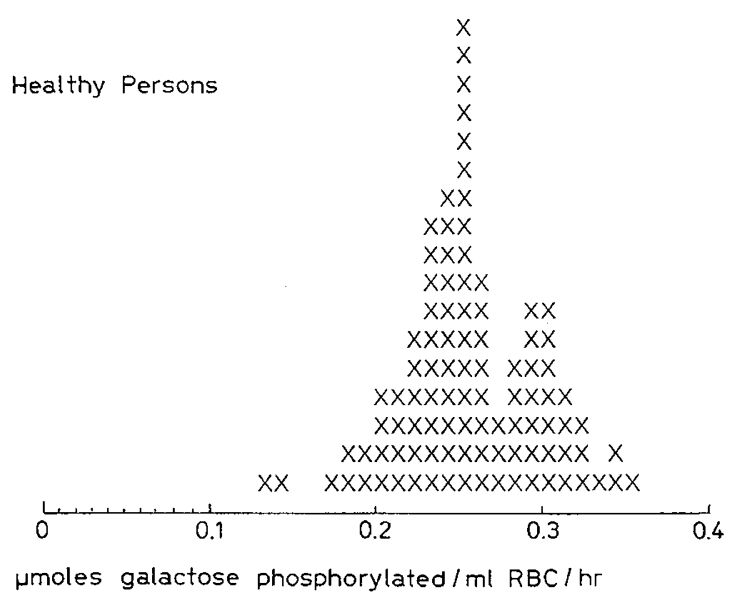

Fig.4. Erythrocyte galactokinase activity of one hundred normal subjects, of family D.-N., consisting of the person with the lowest activity in the control group, her parents and one pair of grandparents; and of family K.-G. of the two galactokinase deficient patients depicted in fig. 3 . 


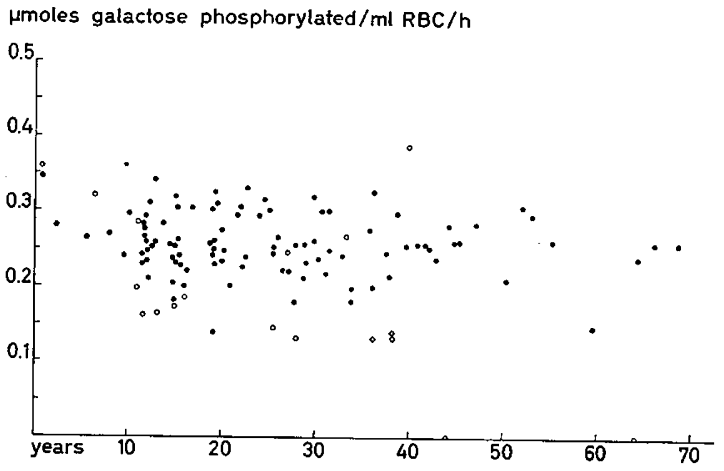

Fig.5. Erythrocyte galactokinase activity, plotted against age, of one hundred normal subjects (closed circles) and of the members of the family with the two persons deficient in galactokinase (open circles).

\section{Discussion}

Galactokinase catalyzes the phosphorylation at the C-1 atom of galactose, the first reaction of the Leloir pathway which is the main road of intermediary galactose metabolism in mammals [10]:

1. galactose- $+\mathrm{ATP}^{1} \rightleftarrows$ galactose-1-phosphate $+\mathrm{ADP}$

The second and third reactions in this sequence are catalyzed by galactose-1-phosphate uridyltransferase and by uridine diphosphogalactose 4-epimerase:

2. galactose-1-phosphate -

UDPG $\rightleftarrows$ UDPGal + glucose-1-phosphate

\section{UDPGal $\rightleftharpoons$ UDPG}

Galactosemia, caused by uridyltransferase deficiency, has thus far been the only hereditary disorder of intermediary galactose metabolism known to occur in man.

In the blood cells of the two patients studied here a virtually complete absence of galactokinase activity has been demonstrated. The inability of whole blood to oxidize galactose- $1-{ }^{14} \mathrm{C}$ (tables I and II) is matched by the absence of galactose-1-phosphate in red cells after incubation with galactose (fig. 1). After milk ingestion, extraction of galactose from the blood in patient H.K. was extremely slow, a fact indicated by the prompt and prolonged rise of blood galactose (fig. 2) and by the substantial loss of galactose in the urine. Thus, one would assume that galactokinase activity in the liver of this patient is absent or at least reduced to a minimum.

\footnotetext{
'ATP = adenosine triphosphate

ADP = adenosine diphosphate

UDPG = uridine diphosphoglucose

$\mathrm{UDPGal}=$ uridine diphosphogalactose
}

Hypergalactosemia and hypergalactosuria are the immediately apparent effects of this biochemical defect. Urinary loss of galartitol in the two patients was suspected since this polyol had been found in lenses [25] and in various tissues [20] of galactose-intoxicated rats. Excretion of galactitol, already considerable after an overnight fast and after an ordinary breakfast (fig.2), was as high as $10.6 \mathrm{~g}$ per day when H.K. ingested 3 liters of milk daily (table III). Two thirds of all dietary galactose was excreted, $1 / 5$ as galactitol and $4 / 5$ as galactose. A full third of the ingested galactose was not accounted for. The metabolic fate of this considerable proportion of the ingested galactose is at present unknown. Several possibilities can be thought of: a) not all ingested galactose was absorbed, b) the biochemical defect was not complete, c) galactitol which had been formed from galactose was further metabolized, d) alternate metabolic routes not involving the formation of galactitol were followed.

Malabsorption of substantial amounts of lactose or of galactose would have caused fermentative diarrhea $[1,19]$; however, no diarrhea occurred. Incompleteness of the biochemical defect can not, of course, be ruled out. Galactitol is formed from galactose by a triphosphopyridine-dependent reductive step involving the activity of an aldose reductase originally demonstrated in seminal vesicles and placenta of the sheep [14], and in lenses [26]. Despite the presence of galactitol in the brain of galactosemic patients [28] and in rats [20], and despite its ready production from galactose by a galactosemic patient as demonstrated by EGAN and WELLS [8], the actual site of production of galactitol found in such tissues is still not known. At present, it is thought that mammals cannot further metabolize it to any significant degree $[10]^{2}$ but there is in fact evidence for an alternative pathway in the utilisation of galactose not involving galactitol. Changes in specificity of ox liver glucose dehydrogenase through purification procedures performed by STRECKer and Korkes [24] have suggested the presence of a galactose dehydrogenase as a contaminant. Cuatrecasas and Segal [7] have now produced evidence and proposed a scheme for an alternate pathway in mammalian liver involving galactonolactone, galactonic acid, its keto-derivative, xylulose and xylulose-5phosphate as intermediates. Perhaps H.K. used such a pathway in disposing of the one third of dietary galactose not accounted for by urinary metabolites.

${ }^{2}$ Note added in proof: Galactitol- ${ }^{14} \mathrm{C}$ when given to normal human individuals, does not appear as ${ }^{14} \mathrm{CO}_{2}$ in expired air, and nearly all the radioactivity is excreted within a few hours, in the urine (S.SEGAL; personal communication). 
Cataract formation appears to be the major deleterious effect of galactokinase deficiency, and of all galactose metabolites galactitol is the one most likely to be involved in cataractogenesis. There is striking similarity of biochemical circumstances in galactokinase deficient patients, galactosemic individuals and in galactose-poisoned laboratory animals: all are characterized by prolonged elevation of galactose levels in body fluids, by production of galactitol, and by formation of cataracts. High activity of aldose reductase, ready availability of its coenzyme reduced triphosphopyridine nucleotide, inability of galactitol to serve as a substrate for polyol dehydrogenase and thus to be metabolized, and its inability to leak out through the lens fiber membranes are the factors favoring the accumulation of this sugar alcohol in the lens [16]. The effects are overhydration, electrolyte and amino acid imbalance which parallel progressive morphological destruction and opacification of the lens. In vivo and in vitro galactitol accumulation in lenses of laboratory animals has been demonstrated [16], and galactitol was present in the lens of a galactosemic infant post mortem [13]. While the accumulation of galactitol in the lenses of individuals deficient in galactokinase has yet to be demonstrated, there is little doubt about the capability of their lenses to accumulate toxic amounts of this polyol.

Little information about the time of the appearance of cataracts in these patients is available. In H.K., cataracts were noticed at the age of 8-9 months but they may have existed long before. The degree of opacification as well as the appearance of secondary cataracts were probably linked to the amount of milk consumed by these patients. If cataracts are the most striking consequence of galactokinase deficiency, the apparent lack of other ill effects of this defect is equally astounding. It is interesting to note in these patients the absence of hyperaminoaciduria, and of mental retardation ${ }^{3}$, both prominent features of untreated galactosemia [29]. The glucosuria in H. K. may reflect competition for reabsorption in the kidney tubule between glucose and galactose rather than a defect of renal tubular reabsorption. The neurofibromatosis of H.K. and of his mother can not at this time be linked with galactokinase deficiency.

${ }^{3}$ Lifelong blindness (in H.K.), poor cultural background, as well as peculiarities of the Gypsy character make the assessment of intelligence in these patients a difficult task. However, it can by safely stated that there is no obvious mental retardation in $\mathrm{H}$. K. or M.F.-K. today. (On the psychology of Gypsies see: H. Arnold: Die Zigeuner [Walter, Olten, Switzerland 1965].)
The results of the assays of erythrocyte galactokinase in the family of the patients when compared with those in the control group (fig. 4 and 5) suggest that the galactokinase deficiency is transmitted as an autosomal recessive trait. The representation of the family of the patients in figure 3 is based on this assumption. It can not be said with certainty whether individual M.D. of the control group (table IV) and one other control person are heterozygotes, but their distinct separation from the other members of this group (fig. 4) would support this assumption.

Nothing is at present known about the incidence of heterozygotes in the population. Why galactokinase deficiency is such a rare disorder and what the effects of the heterozygous state may be are questions open for further investigation. The possibility that the deficiency itself or even the heterozygous state may constitute realizing factors for the formation of cataracts beyond infancy and childhood can not be excluded.

\section{Summary}

The histories of three siblings affected with juvenile cataracts, and clinical and biochemical findings in two of the patients are reported. Inability of blood cells to oxidize galactose and to form phosphorylated intermediates from galactose indicated absence of galactokinase activity in these patients. Small and large loads of dietary galactose caused excretion in urine of galactose and galactitol. One patient, when given 3 liters of milk a day, excreted two thirds of all ingested galactose from milk in the form of galactitol and galactose. Four living children of one of the patients and some other blood relatives had reduced erythrocyte galactokinase activity when compared with one hundred healthy persons. These findings suggest an autosomal recessive mode of inheritance. The role of galactitol in cataractogenesis and possible alternate metabolic paths of intermediary galactose metabolism are discussed.

\section{References and Notes}

1. Anderson, G.M.; Kerry, K.R. and Townley, R.R.W.: An inborn defect of intestinal absorption of certain monosaccharides. Arch. Dis. Ghildh. 40: 1 (1965).

2. Anderson, E.P.; Kalgkar, H.M.; Kurahashi, K. and ISSELBACHER, K.J.: A specific enzymatic assay for the diagnosis of congenital galactosemia. J.Lab.clin. Med. 50: 469 (1957).

3. Bentley, R.; Sweeley, C.C.; Makita, M. and WELLS, W.W.: Gas chromatography of sugars and 
other polyhydroxy compounds. Biochem. Biophys. Res. Commun. 11: 14 (1963).

4. BG betr. Heimatlosigkeit, 3. Dezember, 1850; AS II, 138; BS 1, 99.

5. Beutler, E. and Baluda, M. C.: Improved method for measuring galactose-1-phosphate uridyl transferase activity of erythrocytes. Clin.chim. Acta 13: 369 (1966).

6. Clotten, R. and Clotren, A.: HochspannungsElektrophorese (Thieme, Stuttgart 1962).

7. Guatrescasas, P. and Segal, S.: Galactose conversion to D-xylulose: An alternate route of galactose metabolism. Science 153: 549 (1966).

8. EGAN, T.J. and WELLS, W.W.: Alternate metabolic pathway in galactosemia. Amer. J. Dis. Child. 111: 400 (1966).

9. Fanconi, G.: Hochgradige Galaktose-Intoleranz (Galaktose-Diabetes) bei einem Kinde mit Neurofibromatosis Recklinghausen. Jb.Kinderheilk. 138:1 (1933).

10. Fischer, W. und Wernland, H.: Stoffwechsel der Galaktose und ihrer Derivate (Thieme, Stuttgart 1965).

11. Grtzelmann, R.: Deficiency of erythrocyte galactokinase in a patient with galactose diabetes. Lancet $i i: 670$ (1965).

12. Gitzelmann, R.; Gurtrus, H. G. and Müller, M. : Galactitol excretion in the urine of a galactokinase deficient man. Biochem. Biophys. Res. Commun. 22: 437 (1966).

13. Gitzelmann, R.; Gurtius, H.C. and Schneller, I.: Galactitol and galactose-1-phosphate in the lens of a galactosemic infant. Exp. Eye Res., in press.

14. Hers, H.G.: L'aldose-réductase. Biochim. Biophys. Acta 37: 120 (1960).

15. Khachadurian, A.; Knox, W. E. and Cullen, A.M.: Colorimetric ninhydrin method for total alpha amino acids of urine. J. Lab. clin. Med. 56: 321 (1960).

16. Kinoshita, J.H.: Cataracts in galactosemia. The Jonas S.Friedenwald Memorial Lecture. Invest. Ophthal. 4: 786 (1965).

17. Kirkman, H.N. and Maxwell, E.S.: Enzymatic estimation of erythrocytic galactose-1-phosphate. J.Lab.clin. Med. 56: 161 (1960).

18. NG, W.G.; Donnell, G.N. and Bergren, W.R.: Galactokinase activity in human erythrocytes of individuals at different ages. J. Lab.clin. Med. 66: 115 (1965).

19. Prader, A. and Auricchio, S. : Defects of intestinal disaccharide absorption. Ann. Rev. Med. 16: 345 (1965).

20. QuAn-MA, R. and Wells, W.W.: The distribution of galactitol in tissues of rats fed galactose. Biochem. Biophys. Res. Commun. 20: 486 (1965).

21. Robinson, A.: The assay of galactokinase and galactose-1-phosphate uridyl transferase activity in human erythrocytes. J. exp. Med. 118: 359 (1963).

22. Roth, H.; Segal, S. and Bertour, D.: The quantitative determination of galactose. An enzymic method using galactose oxidase, with applications to blood and other biological fluids. Anal. Biochem. 10: 32 (1965).

23. Sarwarz, V.: A simplified diagnostic test for galactosemia. J. Lab. clin. Med. 56: 483 (1960).

24. Strecker, H.J. and Korkes, S. : Glucose dehydrogenase. J.biol. Chem. 196: 769 (1952).

25. Van Heyningen, R.: Formation of polyols by the lens of the rat with 'sugar' cataract. Nature (Lond.) 184: 194 (1959).

26. Van Heyningen, R.: The sorbitol pathway in the lens. Exp. Eye Res. 1: 396 (1962).

27. Weinberg, A. N. : Detection of congenital galactosemia and the carrier state using galactose $\mathrm{C}^{\mathbf{1 4}}$ and blood cells. Metabolism 10: 728 (1961).

28. Wells, W.W.; Pittmann, T.A.; Wells, H.J. and EGAN, T.J.: The isolation and identification of galactitol from the brains of galactosemic patients. J.biol. Chem. 240: 1002 (1965).

29. WoOLF, L. I. : Inherited metabolic disorders : galactosemia. Advanc. clin. Chem. 5: 1 (1962).

30. The author wishes to express his appreciation to Mr. H. Rellstab for establishing the genealogy of the patients, to Dr. A.C. Mustalish who helped in the family study, to Miss I. Schneller for excellent technical assistance, to Mrs. F.Ferrazzini who located and to Drs. F. Ferrazzini and L. Gilardi who examined patient M.F.-K., to Dr. E.A.Davidson and Dr. H.C. Curtius and his staff for advice, to Dr. M.Aufdermaur for information on patient H.K., to Dr. R.Witmer, chairman of the Department of Ophthalmology, for granting access to the medical records of his department, and to the Sisters at the home for the blind for generous assistance in the metabolic studies performed on patient H.K.

31. Supported in part by Stiftung für wissenschaftliche Forschung an der Universität Zürich, by Grant 3105 of Schweizerischer Nationalfonds zur Förderung der wissenschaftlichen Forschung, and by Julius Klaus-Stiftung, Zürich. 